\title{
The Best Central Adiposity Index in the Prediction of Cardiovascular Risk Factors in South-Western Nigeria
}

\author{
Taiwo Hussean Raimi ${ }^{*}$, Olufemi Fasanmade ${ }^{2}$, Olatunde Odusan ${ }^{3}$, \\ Augustine Efedaye Ohwovoriole ${ }^{2}$ \\ ${ }^{1}$ Department of Medicine, Ekiti State University/Ekiti State University Teaching Hospital, Ado-Ekiti, Nigeria \\ ${ }^{2}$ Department of Medicine, Lagos University Teaching Hospital, Idi-Araba, Nigeria \\ ${ }^{3}$ Department of Medicine, Olabisi Onabanjo University Teaching Hospital, Sagamu, Nigeria \\ Email: *adechristie2004@yahoo.com
}

Received 30 October 2015; accepted 21 December 2015; published 24 December 2015

Copyright (C) 2015 by authors and Scientific Research Publishing Inc.

This work is licensed under the Creative Commons Attribution International License (CC BY).

http://creativecommons.org/licenses/by/4.0/

(c) (i) Open Access

\begin{abstract}
Objective: To determine the best index of central obesity that predicts cardiovascular risk factors (general obesity and hypertension). Methods: A cross-sectional study involving nine hundred and sixteen (443 males and 473 females) participants of a community health survey in Sagamu and Remo-North Local Government Areas of Ogun State, Nigeria. The body mass index (BMI), waist circumference (WC), waist-to-hip ratio (WHR) and waist-to-height ratio (WHtR) of the participants were determined by standard protocols. Pearson correlation between BMI and the three central obesity indices was determined. The area under curve (AUC) on the ROC was used to determine the best measure of central obesity which identified individuals with general obesity and hypertension. Results: WHtR and WC were better than WHR at detecting the presence of both general obesity and hypertension in both males (WHtR vs WHR difference in areas $=0.131$ \} $p<0.0001$; WC vs WHR $\{$ difference in areas $=0.132\} p<0.0001$ ), and females $($ WHtR and WHR difference in areas $=0.214\} \mathrm{p}<0.0001$; WC and WHR \{difference in areas $=0.205\} \mathrm{p}<0.0001$ ). Conclusions: WHtR is as good as WC but better than WHR in identifying individuals with cardiovascular risk factors, and may also be a good criterion to diagnose metabolic syndrome.
\end{abstract}

\section{Keywords}

Central Obesity, Cardiovascular Risk Factors, Prediction

\footnotetext{
"Corresponding author.
}

How to cite this paper: Raimi, T.H., Fasanmade, O., Odusan, O. and Ohwovoriole, A.E. (2015) The Best Central Adiposity Index in the Prediction of Cardiovascular Risk Factors in South-Western Nigeria. Open Journal of Endocrine and Metabolic Diseases, 5, 184-192. http://dx.doi.org/10.4236/ojemd.2015.512023 


\section{Introduction}

Obesity is now a global epidemic, and its comorbidities include coronary heart disease, hypertension and stroke, certain types of cancer, type 2 diabetes mellitus, gallbladder disease, dyslipidemias, osteoarthritis and gout, and pulmonary diseases [1]. Furthermore, it is associated with increased mortality [2] [3]. Fat accumulation occurs in different regions of the body. Body mass index (BMI) is a measure of general obesity, and a well-recognized cardiovascular risk factor [4]-[6].

Central obesity is a measure of visceral fat deposit and can be defined by parameters such as the waist circumference (WC), waist-to-hip ratio (WHR) and waist-to-height ratio (WHtR) [4]. Moreover, measures of central obesity also predict cardiovascular disease, and all-cause mortality [7] [8]. Central obesity is listed as a criterion for diagnosing metabolic syndrome by some authorities. While the International Diabetes Federation (IDF) [9], and National Cholesterol Education Programme Adult Treatment Panel III (NCEP ATP III) [10] recommended the use of waist circumference (WC), the WHO [11] recommended waist-to-hip ratio (WHR) as a measure of central obesity. Recently, waist-to-height ratio (WHtR) was proposed as a good measure of central obesity, and suggested as an alternative to WC, because unlike WC, it took into account differences in body height [12] [13]. Furthermore, it has been suggested that the predictive power of anthropometric indices is population-dependent, and varies across ethnic groups [14].

While many workers [14]-[18] in different parts of the world have compared the relationship between the three measures of central obesity and CVD risk factors, there are no such reports in Nigeria. Rather, there is a report comparing the ability of WC and WHR to predict cardiovascular risk factors [19]. Thus, the best index of central obesity has not been determined in our environment, and the knowledge of this will aid the clinicians in the diagnosis of metabolic syndrome.

The aim of the study was to determine the correlation between indices of central obesity and body mass index, and the measure of central obesity that best identifies individuals with cardiovascular risk factors (body mass index and systemic hypertension).

\section{Methods}

\subsection{Study Design and Participants}

This is a cross-sectional descriptive survey. The study was conducted at Sagamu and Remo North local government area of Ogun State, Nigeria. The locations were chosen by convenience sampling. Approval for the study was obtained from the ethic and research committee of the Olabisi Onabanjo University Teaching Hospital, Sagamu, Ogun State. The consent of the king and community leaders was also sought. The consent of each participant was also obtained. The participants were apparently healthy individuals aged 20 - 70 years. The participants included market men and women, artisans, farmers, drivers, and civil servants. Initial sensitization visits were paid to the communities, and the people that met the inclusion criteria were told to meet at designated points such as motor parks, town hall or the king's palace for screening. All the people who gave their consent were included in the study. Individuals who are wheelchair bound, pregnant women and lactating mothers were excluded.

\subsection{Procedure and Measurements}

Trained assistants helped with data collection and measurements.

\subsubsection{Anthropometric Measurements}

The height, weight, waist and hip circumferences and blood pressure were determined. The height was measured (in metres) to the nearest 0.1 metre with a calibrated meter rule placed horizontally against the wall, with the participants barefooted [20]. The weight was measured (in kilograms) with a weighing scale (Surgifriend Medicals, England) without shoes and with the patient wearing light clothing, to the nearest $0.1 \mathrm{~kg}$ [20]. The Body Mass Index (BMI) was taken as the ratio of weight $(\mathrm{kg})$ to the square of the height $\left(\mathrm{m}^{2}\right)$ [20]. The waist circumference (in centimetres) was taken midway between the inferior margin of the last rib and the iliac crest in a horizontal plane. The circumferences were measured to the nearest centimetre at the end of normal expiration [20]. Hip circumference was measured to the nearest centimetres at the level of the greater trochanters with the subjects wearing underwear or light clothing. The waist-to-hip ratio (WHR) was calculated from the values of 
the waist and hip circumferences [20]. Waist-to-height ratio (WHtR) was calculated from the values of waist circumference and height in centimetres.

\subsubsection{Blood Pressure Measurement}

The blood pressure was measured once with a standard mercury sphygmomanometer (Accossons, England), with the subjects in the sitting position and the arm resting on a table at the same level of the heart. The first and fifth Korotkoff sounds were taken as the systolic and diastolic blood pressures respectively.

\subsubsection{Definition of Cardiovascular Risk Factors}

Generalized obesity and systemic hypertension were regarded as cardiovascular risk factors. Generalized obesity was defined as BMI $\geq 30 \mathrm{~kg} / \mathrm{m}^{2}$ [20], while systemic hypertension was defined as systolic blood pressure of $\geq 140 \mathrm{mmHg}$ and/or diastolic blood pressure of $\geq 90 \mathrm{mmHg}$ [21].

\subsection{Statistical and Data Analysis}

Data were analysed using the statistical package for social sciences (SPSS) version 20.0 (Chicago, Illinois, USA). Continuous variables were expressed as means and standard deviation. Pearson correlation between BMI and the three central obesity indices was determined. MedCalc Statistical Software version 14.8.1 (MedCalc Software, Ostend, Belgium, 2014) was used to generate Receiver Operative Characteristics (ROC) Curve, in order to determine and compare the ability of the measures of central obesity to identify persons with generalized obesity and systemic hypertension. The area under curve (AUC) on the ROC was used to determine the best measure of central obesity which identifies individuals with generalized obesity and systemic hypertension.

\section{Results}

The participants' clinical characteristics are shown in Table 1. They were made up of 443 (48.4\%) males, mean age $40.56 \pm 13.59$ years and $473(51.6 \%)$ females, mean age $46.81 \pm 15.49$ years. The female participants were significantly older, and had greater BMI, WC, WHR, and WHtR than their male counterparts ( $\mathrm{p}=0.002$ for WC, and $\mathrm{p}<0.001$ for BMI, WHR and WHtR). There were no significant differences between the systolic and diastolic blood pressures of both genders $(\mathrm{p}>0.05)$.

\subsection{Correlation between Central and General Obesity}

Among the male participants, WC and WHtR correlated better with BMI compared with WHR, $(r=0.860, p<$ $0.001 \mathrm{vs} r=0.490, \mathrm{p}<0.001)$. Among the female participants, the correlation between indices of central and general obesity was best with WC, $(\mathrm{r}=0.895, \mathrm{p}<0.001)$. There was a strong correlation among the three indices of central obesity (Table 2).

Table 1. Clinical characteristics of the study population.

\begin{tabular}{ccccc}
\hline Characteristics & Females $\mathbf{n}=\mathbf{4 7 3}$ & Males $\mathbf{n}=\mathbf{4 4 3}$ & Total $\mathbf{n}=\mathbf{9 1 6}$ & p-value \\
\hline Age (years) & $43.8(14.9)$ & $40.5(13.6)$ & $46.8(15.5)$ & $<0.001$ \\
BMI $\left(\mathrm{kg} / \mathrm{m}^{2}\right)$ & $24.8(5.3)$ & $23.7(3.9)$ & $25.8(6.1)$ & $<0.001$ \\
WC (cm) & $84.5(13.0)$ & $83.1(11.8)$ & $85.8(13.9)$ & $<0.01$ \\
HC (cm) & $93.6(11.0)$ & $90.7(8.9)$ & $93.6(11.0)$ & $<0.001$ \\
WHR & $0.90(0.07)$ & $0.91(0.07)$ & $0.89(0.07)$ & $<0.001$ \\
WHtR & $0.52(0.09)$ & $0.49(0.07)$ & $0.55(0.09)$ & $<0.001$ \\
SBP (mmHg) & $132.0(24.7)$ & $133.4(22.9)$ & $130.69(26.2)$ & $>0.05$ \\
DBP (mmHg) & $80.7(14.9)$ & $81.6(14.1)$ & $79.9(15.6)$ & $>0.05$ \\
\hline
\end{tabular}

Data are means (SD), BMI, body mass index; WC, waist circumference; WHtR, waist-to-height ratio; WHR, waist-to-hip ratio; DBP, diastolic blood pressure; SBP, systolic blood pressure. 


\subsection{Prediction of Cardiovascular Risk Factors}

Figure 1 shows the Area under the Curve (AUC) of WC, WHR, and WHtR on the Receiver Operating Characteristics (ROC) curve (of male participants) for predicting general obesity and systemic hypertension. Figure 2 shows the AUC of WC, WHR, and WHtR on the ROC curve (of female participants) for predicting general obesity and systemic hypertension. In both genders, the areas were significantly greater than 0.5 (half of the total area) for the three obesity indices ( $\mathrm{p}<0.001$ ). The AUC of WC and WHtR were however greater than that of WHR.

The values of the Areas Under the Curve (AUC) for predicting the presence of general obesity, hypertension, or general obesity/hypertension are shown in Table 3. In most cases the absolute value of AUC of WHtR was greater than those of WC and WHR. Among the three indices of obesity waist-to-hip ratio has the smallest AUC, suggesting that it predicted cardiovascular risk factors less than WC or WHtR.

Table 4 compares the AUC for detecting both general obesity and systemic hypertension. It showed that WHtR and WC were better than WHR at detecting the presence of both general obesity and hypertension in both males (WHtR and WHR \{difference in areas $=0.131\} \mathrm{p}<0.0001$; WC and WHR \{difference in areas $=0.132$ \} $\mathrm{p}<0.0001$ ), and females (WHtR and WHR \{difference in areas $=0.214$ \} $\mathrm{p}<0.0001$; WC and WHR \{difference in areas $=0.205\} \mathrm{p}<0.0001)$. The AUC of WHtR and WC on the ROC for identifying the presence of both general obesity and hypertension were not significantly different in both genders $(p>0.05)$.

Table 2. Correlation matrix between general and central obesity among the participants.

\begin{tabular}{ccccc}
\hline Obesity indices & BMI & WC & WHR & WHtR \\
\hline BMI & - & Females & & \\
WC & 0.895 & - & - & - \\
WHR & 0.408 & 0.676 & 0.685 & \\
WHtR & 0.888 & 0.971 & & \\
& & Males & & \\
BMI & - & & - & - \\
WC & 0.860 & - & 0.776 \\
WHR & 0.490 & 0.737 & \\
WHtR & 0.860 & 0.958 & \\
\hline
\end{tabular}

BMI, body mass index; WC, waist circumference; WHtR, waist-to-height ratio; WHR, waist-to-hip ratio. p $<0.001$ for all the correlations.

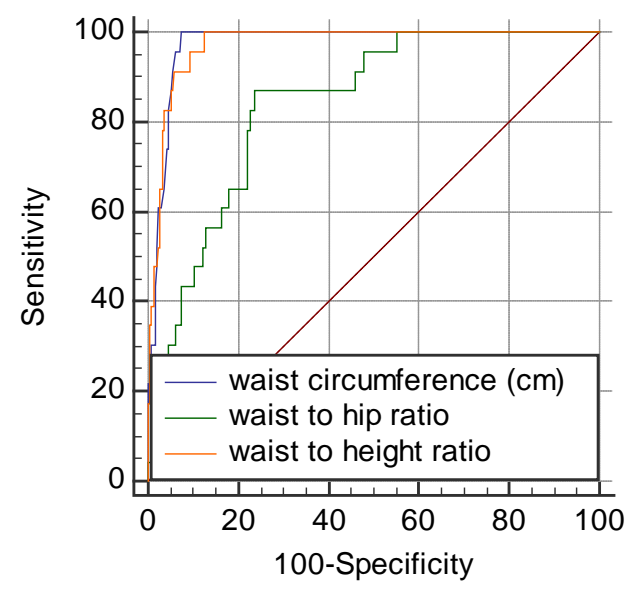

Figure 1. Receiver Operating Characteristic (ROC) curve of waist circumference, waist-to-hip ratio and waist-to-height ratio for predicting general obesity and hypertension in males. 


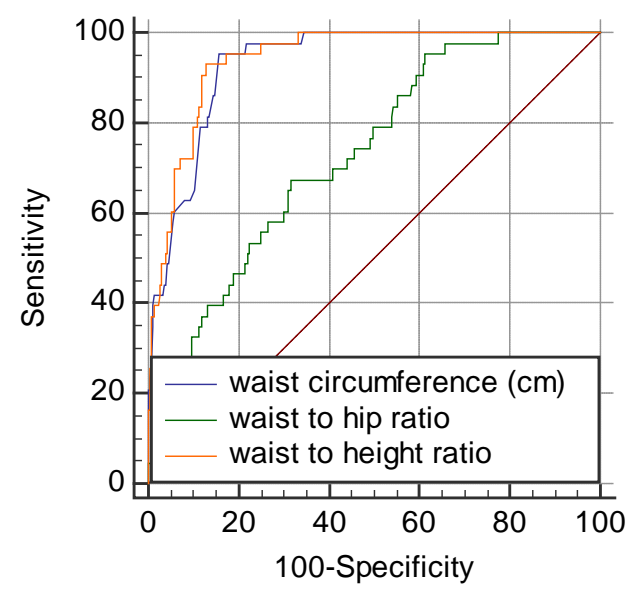

Figure 2. Receiver Operating Characteristic (ROC) curve of waist circumference, waist-to-hip ratio and waist-to-height ratio for predicting general obesity and hypertension in females.

Table 3. Areas Under the Curve (AUC) for predicting the presence of general obesity, hypertension, or general obesity/ hypertension.

\begin{tabular}{ccccccc}
\hline $\begin{array}{c}\text { Indices of } \\
\text { central obesity }\end{array}$ & \multicolumn{2}{c}{$\begin{array}{c}\text { Generalized } \\
\text { obesity }\end{array}$} & \multicolumn{2}{c}{ Hypertension } & \multicolumn{2}{c}{$\begin{array}{c}\text { Obesity and } \\
\text { hypertension }\end{array}$} \\
\hline Males & AUC & $95 \%$ CI & AUC & $95 \%$ CI & AUC & $95 \%$ CI \\
WC & 0.97 & $0.95-0.98$ & 0.70 & $0.66-0.75$ & 0.97 & $0.95-0.99$ \\
WHR & 0.79 & $0.74-0.82$ & 0.67 & $0.63-0.72$ & 0.84 & $0.80-0.87$ \\
WHtR & 0.97 & $0.95-0.99$ & 0.71 & $0.67-0.75$ & 0.97 & $0.95-0.99$ \\
Females & & & & & \\
WC & 0.97 & $0.95-0.99$ & 0.64 & $0.60-0.69$ & 0.93 & $0.91-0.95$ \\
WHR & 0.74 & $0.70-0.78$ & 0.63 & $0.60-0.68$ & 0.73 & $0.69-0.77$ \\
WHtR & 0.98 & $0.96-0.99$ & 0.67 & $0.62-0.71$ & 0.94 & $0.92-0.96$ \\
\hline
\end{tabular}

$\mathrm{p}<0.001$ for all the AUCs, AUC: area under the curve, CI: confidence interval.

Table 4. Pairwise comparison of AUC on the ROC of central obesity indices in identifying both general obesity and hypertension for males and females.

\begin{tabular}{lll}
\hline & Males & Females \\
\hline WC $\sim$ WHtR & & 0.00922 \\
Difference between areas & 0.000828 & $-0.00304-0.0215$ \\
$95 \%$ CI & $-0.0103-0.0119$ & 1.474 \\
z statistic & 0.146 & $\mathrm{p}=0.1403$ \\
Significance level & $\mathrm{p}=0.8837$ & \\
WC $\sim$ WHR & & 0.205 \\
Difference between areas & 0.132 & $0.144-0.265$ \\
$95 \%$ CI & $0.0683-0.196$ & 6.621 \\
z statistic & 4.062 & $\mathrm{p}<0.0001$ \\
Significance level & $\mathrm{p}<0.0001$ & \\
WHtR $\sim$ WHR & & 0.214 \\
Difference between areas & 0.131 & $0.155-0.273$ \\
$95 \%$ CI & $0.0705-0.192$ & 7.054 \\
z statistic & 4.232 & $\mathrm{p}<0.0001$ \\
Significance level & $\mathrm{p}<0.0001$ & \\
\hline
\end{tabular}


The AUC of WHtR and WC on the ROC for identifying the presence of both general obesity and hypertension were not significantly different in both genders $(\mathrm{p}>0.05)$.

\section{Discussion}

To our knowledge, this is the first study to evaluate the performance of three central obesity indices in identifying cardiovascular risk factors our environment. Previous study compared the performance of WC and WHR in identifying cardiovascular risk factors [19].

The goals of our study were to determine the correlation between the indices of central obesity and body mass index, and determine the central obesity index that best identify cardiovascular risk factors (generalized obesity and systemic hypertension).

The female participants had greater mean BMI, WC, WHR and WHtR compared with the males. This is in agreement with previous local and foreign studies [22] [23]. Men are generally more active than women. While more men engage in manual labour and farming activities, women engage in sedentary work such as market trading. Other possible contributors to the gender difference in the obesity include age, nutritional and biological factors [24].

\subsection{Correlation between Indices of Central and General Obesity}

Consistent with previous reports [25], there was a good correlation between body mass index and the indices of central obesity. Among the female participants, WC and WHtR correlated equally with BMI but both correlated better than WHR. This observation is similar to the report by previous authors [26]. This is not unexpected since both indices are measures of adiposity.

\subsection{Identification of Cardiovascular Risk Factors}

The ROC revealed that whereas, WHtR has the largest AUC in most instances, WHR has the smallest AUC. This suggests that WHtR identified individuals with cardiovascular risk factors better than WC and WHR. However subjecting the differences in the AUC to further analysis revealed that there was no significant difference between the AUC of WHtR and WC, whereas the AUC of WHR was significantly smaller than that of the other two indices of central obesity. This indicates that WHtR was as good as WC, and both were better than WHR in identifying individuals with cardiovascular risk factors. This is true in both men and women for identification of both general obesity and hypertension.

Previous studies that compared the ability of indices of central obesity to identify CVD risk factors yielded inconsistent results. Similar to our findings, a Nigerian study which compared the ability of WC and WHR to predict CVD risk factors found that WC was better than WHR [19]. However, the above study did not test the predictive ability of WHtR.

Bener et al., [17] in a study conducted in Qatar found that WC performed better than WHR and WHtR in identifying people with metabolic syndrome in both men and women. However, some researchers [16] [27] [28] [29] found that WHR predicted CVD risk factors better that WC in Turkey and Australia. Other studies conducted in Iran, Jordan, China, Chinese Taipei and Europe found that WHtR either identified [18] [30], or predicted [15] [31] [32] cardiovascular risk factors than other central obesity indices.

Contrary to the above reports none of the three indices of obesity were found to be superior in predicting CVD by other workers in America and New Zealand [7] [33]. These inconsistencies may be due to different geographical locations and or methodologies. Indeed, it has been observed that ethnicity and race influence the cut-off points and/or use of different anthropometric indices to diagnose obesity and metabolic syndrome [34]. Ethnicity significantly affects the associations between anthropometric indices used to assess adiposity such as BMI and WC. This underscores the need for ethnic specific cut-off for WC in the definition of metabolic syndrome proposed by the IDF [9]. Lower cut-off for BMI was also proposed for the Asians who have smaller body frames, are more insulin resistant, and have greater body fat for the same BMI than the Caucasians [35]-[37]. Furthermore, ethnicity influences the association between anthropometric obesity measures and cardiovascular risk factors [38]. Molarius et al., therefore, suggested that the predictive power of anthropometric indices is ethnic and population-dependent [14]. In view of the above, it has also been suggested that ethnic-specific assessment, prevention and treatment of CVD risk be developed [8] [39].

Apart from geographical locations, methodological differences in the above studies may also contribute to 
different conclusions. While some studies were prospective, others were cross-sectional in design.

\section{Strengths, Limitations and Future Directions}

The cross-sectional design of this research makes it difficult to establish a causal relationship between the parameters studied. Ability to predict other cardiometabolic factors such as serum Triglycerides and HDL-cholesterol were not studied. The findings of the study may not apply to the other parts of the country because of her multi-ethnic populations. A study involving other ethnic groups is necessary to confirm our findings.

\section{Conclusion}

WHtR is as good as WC but better than WHR in identifying individuals with cardiovascular risk factors, and may also be a good criterion to diagnose metabolic syndrome.

\section{References}

[1] World Health Organization (2000) Obesity: Preventing and Managing the Global Epidemic. Report of a WHO Consultation. World Health Organ Technical Report Series 894, i-xii, 1-253. http://whqlibdoc.who.int/trs/WHO_TRS_894_\%28part1\%29.pdf

[2] Flegal, K.M., Kit, B.K., Orpana, H. and Graubard, B.I. (2013) Association of All-Cause Mortality with Overweight and Obesity Using Standard Body Mass Index Categories: A Systematic Review and Meta-Analysis. JAMA, 309, 7182. http://dx.doi.org/10.1001/jama.2012.113905

[3] Chen, Y., Copeland, W.K., Vedanthan, R., Grant, E., Lee, J.E., Gu, D., et al. (2013) Association between Body Mass Index and Cardiovascular Disease Mortality in East Asians and South Asians: Pooled Analysis of Prospective Data from the Asia Cohort Consortium. BMJ, 347, f5446. http://dx.doi.org/10.1136/bmj.f5446

[4] Huang, K.C., Lin, W.Y., Lee, L.T., et al. (2002) Four Anthropometric Indices and Cardiovascular Risk Factors in Taiwan. International Journal of Obesity and Related Metabolic Disorders, 26, 1060-1068. http://dx.doi.org/10.1038/sj.ijo.0802047

[5] Farin, H.M., Abbasi, F. and Reaven, G.M. (2006) Comparison of Body Mass Index versus Waist Circumference with the Metabolic Changes That Increase the Risk of Cardiovascular Disease in Insulin-Resistant Individuals. American Journal of Cardiology, 98, 1053-1056. http://dx.doi.org/10.1016/j.amjcard.2006.05.025

[6] Sung, K.C., Ryu, S. and Reaven, G.M. (2007) Relationship between Obesity and Several Cardiovascular Disease Risk Factors in Apparently Healthy Korean Individuals: Comparison of Body Mass Index and Waist Circumference. Metabolism: Clinical and Experimental, 56, 297-303. http://dx.doi.org/10.1016/j.metabol.2006.09.016

[7] Page, J.H., Rexrode, K.M., Hu, F., Albert, C.M., Chae, C.U. and Manson, J.E. (2009) Waist-Height Ratio as a Predictor of Coronary Heart Disease among Women. Epidemiology, 20, 361-366. http://dx.doi.org/10.1097/EDE.0b013e31819f38f1

[8] Goh, L.G., Dhaliwal, S.S., Welborn, T.A., Lee, A.H. and Della, P.R. (2014) Anthropometric Measurements of General and Central Obesity and the Prediction of Cardiovascular Disease Risk in Women: A Cross-Sectional Study. BMJ Open, 4, e004138. http://dx.doi.org/10.1136/bmjopen-2013-004138

[9] Alberti, K.G., Zimmet, P. and Shaw, J. (2005) The Metabolic Syndrome-A New Worldwide Definition. Lancet, 366, 1059-1062. http://dx.doi.org/10.1016/S0140-6736(05)67402-8

[10] Expert Panel on Detection, Evaluation, and Treatment of High Blood Cholesterol in Adults (2001) Executive Summary of the Third Report of the National Cholesterol Education Program (NCEP) Expert Panel on Detection, Evaluation, and Treatment of High Blood Cholesterol in Adults (Adult Treatment Panel III). JAMA, 285, 2486-2497. http://dx.doi.org/10.1001/jama.285.19.2486

[11] World Health Organization (1999) Definition and Diagnosis of Diabetes Mellitus and Intermediate Hyperglycemia: Report of a WHO Consultation. World Health Organization, Geneva. http://www.who.int/diabetes/publications/Definition\%20and\%20diagnosis\%20of\%20diabetes_new.pdf

[12] Ashwell, M., Gunn, P. and Gibson, S. (2012) Waist-to-Height Ratio Is a Better Screening Tool than Waist Circumference and BMI for Adult Cardiometabolic Risk Factors: Systematic Review and Meta-Analysis. Obesity Reviews, 13, 275-286. http://dx.doi.org/10.1111/j.1467-789X.2011.00952.x

[13] Browning, L.M., Hsieh, S.D. and Ashwell, M. (2010) A Systematic Review of Waist-to-Height Ratio as a Screening Tool for the Prediction of Cardiovascular Disease and Diabetes: 0.5 Could Be a Suitable Global Boundary Value. Nutrition Research Reviews, 23, 247-269. http://dx.doi.org/10.1017/S0954422410000144

[14] Molarius, A. and Seidell, J.C. (1998) Selection of Anthropometric Indicators for Classification of Abdominal Fat- 
ness-A Critical Review. International Journal of Obesity, 22, 719-727. http://dx.doi.org/10.1038/sj.ijo.0800660

[15] Hadaegh, F., Zabetian, A., Harati, H. and Azizi, F. (2006) Waist/Height Ratio as a Better Predictor of Type 2 Diabetes Compared to Body Mass Index in Tehranian Adult Men-A 3.6-Year Prospective Study. Experimental and Clinical Endocrinology \& Diabetes, 114, 310-315. http://dx.doi.org/10.1055/s-2006-924123

[16] Esmaillzadeh, A., Mirmiran, P. and Azizi, F. (2004) Waist-to-Hip Ratio Is a Better Screening Measure for Cardiovascular Risk Factors than Other Anthropometric Indicators in Tehranian Adult Men. International Journal of Obesity, 28, 1325-1332. http://dx.doi.org/10.1038/sj.ijo.0802757

[17] Bener, A., Yousafzai, M.T., Darwish, S., Al-Hamaq, A.O., Nasralla, E.A. and Abdul-Ghani, M. (2013) Obesity Index That Better Predict Metabolic Syndrome: Body Mass Index, Waist Circumference, Waist Hip Ratio, or Waist Height Ratio. Journal of Obesity, 2013, Article ID: 269038. http://dx.doi.org/10.1155/2013/269038

[18] Xu, Z., Qi, X., Dahl, A.K. and Xu, W. (2013) Waist-to-Height Ratio Is the Best Indicator for Undiagnosed Type 2 Diabetes. Diabetic Medicine, 30, e201-e207. http://dx.doi.org/10.1111/dme.12168

[19] Okafor, C.I., Fasanmade, O., Ofoegbu, E. and Ohwovoriole, A.E. (2011) Comparison of the Performance of Two Measures of Central Adiposity among Apparently Healthy Nigerians Using the Receiver Operating Characteristic Analysis. Indian Journal of Endocrinology and Metabolism, 15, 320-326. http://dx.doi.org/10.4103/2230-8210.85588

[20] World Health Organization (1995) Technical Report Series No. 854. Physical Status: The Use and Interpretation of Anthropometry. WHO, Geneva. http://www.who.int/childgrowth/publications/physical_status/en/

[21] Chobanian, A.V., Bakris, G.L., Black, H.R., Cushman, W.C., Green, L.A., Izzo Jr., J.L., et al. (2003) The Seventh Report of the Joint National Committee on Prevention, Detection, Evaluation, and Treatment of High Blood Pressure: The JNC 7 Report. JAMA, 289, 2560-2572. http://dx.doi.org/10.1001/jama.289.19.2560

[22] Adedoyin, R.A., Mbada, C.E., Balogun, M.O., Adebayo, R.A., Martins, T. and Ismail, S. (2009) Obesity Prevalence in Adult Residents of Ile-Ife, Nigeria. Nigerian Quarterly Journal of Hospital Medicine, 19, 100-105.

[23] Pettersson, J., Johansson, K., Rossner, S. and Neovius, M. (2008) Prevalence of Obesity and Abdominal Obesity in Swedish Primary Care and Occupational Health Clinics. Obesity Facts, 1, 251-257. http://dx.doi.org/10.1159/000156530

[24] Knopp, R.H., Paramsothy, P., Retzlaff, B.M., Fish, B., Walden, C., Dowdy, A., et al. (2005) Gender Differences in Lipoprotein Metabolism and Dietary Response: Basis in Hormonal Differences and Implications for Cardiovascular Disease. Current Atherosclerosis Reports, 7, 472-479. http://dx.doi.org/10.1007/s11883-005-0065-6

[25] Liu, A., Abbasi, F. and Reaven, G. (2011) Adiposity Indices in the Prediction of Metabolic Abnormalities Associated with Cardiovascular Disease in Non-Diabetic Adults. Nutrition, Metabolism and Cardiovascular Diseases, 21, 553-560. http://dx.doi.org/10.1016/j.numecd.2009.12.009

[26] Kurpad, S.S., Tandon, H. and Srinivasan, K. (2003) Waist Circumference Correlates Better with Body Mass Index than Waist-to-Hip Ratio in Asian Indians. The National Medical Journal of India, 16, 189-192.

[27] Dalton, M., Cameron, A.J., Zimmet, P.Z., Shaw, J.E., Jolley, D., Dunstan, D.W., et al. (2003) Waist Circumference, Waist-Hip Ratio and Body Mass Index and Their Correlation with Cardiovascular Disease Risk Factors in Australian Adults. Journal of Internal Medicine, 254, 555-563. http://dx.doi.org/10.1111/j.1365-2796.2003.01229.x

[28] Akpinar, E., Bashan, I., Bozdemir, N. and Saatci, E. (2007) Which Is the Best Anthropometric Technique to Identify Obesity: Body Mass Index, Waist Circumference or Waist-Hip Ratio? Collegium Antropologicum, 31, 387-393.

[29] Schneider, H.J., Friedrich, N., Klotsche, J., Pieper, L., Nauck, M., John, U., et al. (2010) The Predictive Value of Different Measures of Obesity for Incident Cardiovascular Events and Mortality. The Journal of Clinical Endocrinology \& Metabolism, 95, 1777-1785. http://dx.doi.org/10.1210/jc.2009-1584

[30] Khader, Y.S., Batieha, A., Jaddou, H., Batieha, Z., El-Khateeb, M. and Ajlouni, K. (2010) Anthropometric Cut-Off Values for Detecting Metabolic Abnormalities in Jordanian Adults. Diabetes, Metabolic Syndrome and Obesity: Targets and Therapy, 3, 395-402. http://dx.doi.org/10.2147/DMSOTT.S15154

[31] Lin, W.Y., Lee, L.T., Chen, C.Y., Lo, H., Hsia, H.H., Liu, I.L., Lin, R.S., Shau, W.Y. and Huang, K.C. (2002) Optimal Cut-Off Values for Obesity: Using Simple Anthropometric Indices to Predict Cardiovascular Risk Factors in Taiwan. International Journal of Obesity, 26, 1232-1238. http://dx.doi.org/10.1038/sj.ijo.0802040

[32] Song, X., Jousilahti, P., Stehouwer, C.D., Söderberg, S., Onat, A., Laatikainen, T., et al. (2013) Comparison of Various Surrogate Obesity Indicators as Predictors of Cardiovascular Mortality in Four European Populations. European Journal of Clinical Nutrition, 67, 1298-1302. http://dx.doi.org/10.1038/ejcn.2013.203

[33] Taylor, R.W., Brooking, L., Williams, S.M., Manning, P.J., Sutherland, W.H., Coppell, K.J., Tipene-Leach, D., Dale, K.S., McAuley, K.A. and Mann, J.I. (2010) Body Mass Index and Waist Circumference Cutoffs to Define Obesity in Indigenous New Zealanders. The American Journal of Clinical Nutrition, 92, 390-397. http://dx.doi.org/10.3945/ajcn.2010.29317 
[34] Ko, K.P., Oh, D.K., Min, H., Kim, C.S., Park, J.K., Kim, Y. and Kim, S.S. (2012) Prospective Study of Optimal Obesity Index Cutoffs for Predicting Development of Multiple Metabolic Risk Factors: The Korean Genome and Epidemiology Study. Journal of Epidemiology, 22, 433-439.

[35] Ko, G.T., Tang, J., Chan, J.C., Sung, R., Wu, M.M.F., Wai, H.P.S. and Chen, R. (2001) Lower BMI Cut-Off Value to Define Obesity in Hong Kong Chinese: An Analysis Based on Body Fat Assessment by Bioelectrical Impedance. British Journal of Nutrition, 85, 239-242. http://dx.doi.org/10.1079/BJN2000251

[36] Banerji, M.A., Faridi, N., Atluri, R., Chaiken, R.L. and Lebovitz, H.E. (1999) Body Composition, Visceral Fat, Leptin, and Insulin Resistance in Asian Indian Men. The Journal of Clinical Endocrinology \& Metabolism, 84, 137-144. http://dx.doi.org/10.1210/jc.84.1.137

[37] Hsu, W.C., Araneta, M.R., Kanaya, A.M., Chiang, J.L. and Fujimoto, W. (2015) BMI Cut Points to Identify At-Risk Asian Americans for Type 2 Diabetes Screening. Diabetes Care, 38, 150-158. http://dx.doi.org/10.2337/dc14-2391

[38] Lear, S.A., Toma, M., Birmingham, C.L. and Frohlich, J.J. (2003) Modification of the Relationship between Simple Anthropometric Indices and Risk Factors by Ethnic Background. Metabolism-Clinical and Experimental, 52, 12951301. http://dx.doi.org/10.1016/S0026-0495(03)00196-3

[39] Wang, Y. and Beydoun, M.A. (2007) The Obesity Epidemic in the United States-Gender, Age, Socioeconomic, Racial/Ethnic, and Geographic Characteristics: A Systematic Review and Meta-Regression Analysis. Epidemiologic Reviews, 29, 6-28. http://dx.doi.org/10.1093/epirev/mxm007 